\title{
Curiosidades vivas. Los animales de América y Filipinas en la Ménagerie real durante el siglo XVIIII/
}

\author{
Living Curiosities. The Animals from Spanish America \\ and the Philippines in the Royal Menagerie \\ during the Eighteenth Century
}

Carlos Gómez-Centurión Jiménez

Universidad Complutense de Madrid

El artículo analiza el importante papel desempeñado por los animales procedentes de la América española y de Filipinas en las colecciones zoológicas reales durante el siglo XVIII. Además de las especies que con mayor frecuencia estuvieron presentes en dichas colecciones y sus criterios de selección, se estudian los mecanismos clientelares y políticos que propiciaban su envío hasta la corte madrileña, así como los numerosos obstáculos que era necesario sortear para que los animales lograran sobrevivir a la travesía transoceánica.

Palabras clave: Animales exóticos; América española; Filipinas; Ménagerie real; Corte española; Siglo XVIII.

The article analyzes the important role of animals from Spanish America and the Philippines in Royal zoological collections during the $18^{\text {th }}$ Century. It studies not only the species that were included more frequently in the collections and the criteria for their selection, but also the political and lobbying mechanisms devised for their shipment to the Madrid Court. The article also describes the many obstacles that had to be overcome in order to ensure the survival of the animals in their transoceanic journey.

KeYwords: Exotic Animals; Spanish America; Philippines; Royal Menagerie; Spanish Court; Eighteenth Century. 


\section{Un coleccionismo de prestigio ${ }^{1}$}

"En todos los tiempos ha sido muy propio de los soberanos para ostentación de su grandeza tener en sus palacios y casas reales aquellos animales, plantas y frutos más extraños y particulares que se crían en otros países". Con estas palabras comenzaba Juan Antonio Álvarez de Quindós uno de los capítulos de su Descripción histórica del Real Bosque y Casa de Aranjuez, dedicado en este caso a referir cuantos animales extraños y curiosos había habido en aquel real sitio durante el reinado de Carlos III, entre los cuales alcanzaba a recordar la presencia de una cíbola procedente de México, guanacos de Chile, "una vaca enana y un buey que criaba un ternero, cosa harto extraña", y los magníficos elefantes asiáticos que durante muchos años fueron las grandes joyas de la colección zoológica del monarca. ${ }^{2} \mathrm{Y}$ es que coleccionar este tipo de criaturas constituía en la corte española una tradición antiquísima que hundía sus orígenes en los siglos medievales, ${ }^{3}$ se había propagado con fuerza en época de los Austrias ${ }^{4}$ y alcanzado

1 El presente artículo se inscribe dentro del proyecto de investigación Vida y cultura cortesana en la España Moderna (HUM2005-03137/HIST) financiado por el MEC.

2 Juan Antonio Álvarez de Quindós: Descripción histórica del Real Bosque y Casa de Aranjuez, Madrid, 1804, ed. facsímil, Aranjuez, Doce Calles, 1993, pp. 333-335. Sobre la historia del coleccionismo de animales, la obra más amplia sigue siendo la de Gustave Loisel: Histoire des ménageries de l'antiquité à nos jours, 3 vols., Paris, O. Doin, 1912. Desde un punto de vista historiográfico más actual: R. G. Hoage y William A. Deiss (eds.): New Worlds, New Animals. From Menagerie to Zoological Park in the Nineteenth Century, Baltimore, John Hopkins University Press, 1996; Eric Baratay y Elizabeth Hardouin-Fugier: Zoo: A History of Zoological Gardens in the West, ed. inglesa, London, Reaktion Books, 2002.

3 Anna Maria Adroer i Tassis: "Animals exòtics als palaus reials de Barcelona", en Medievalia, 8, Barcelona, 1989, pp. 9-22; Dolores Carmen Morales Muñiz: "La fauna exótica en la Península Ibérica: apuntes para el estudio del coleccionismo animal en el Medievo hispánico", en Espacio, Tiempo y Forma, Serie III, H. ${ }^{a}$ Medieval, 13, Madrid, 2000, pp. 233-270.

4 El coleccionismo de animales de los Austrias ha sido abordado parcialmente hasta ahora sólo por especialistas de la historia del arte: Miguel Morán y Fernando Checa: El coleccionismo en España. De la cámara de las maravillas a la galería de pinturas, Madrid, Cátedra, 1985. El primer artículo monográfico dedicado a esta cuestión ha sido el de Annemarie Jordan Gschwend y Almudena Pérez de Tudela: "Renaissance Ménageries: Exotic Animals and Pets at the Habsburg Courts in Iberia and Central Europe", en Karl A. E. Enenkel y Paul J. Smith (eds.): Early Modern Zoology. The Construction of Animals in Science, Literature and Visual Arts, Leiden, Brill, 2007, pp. 419-447, pero dichas autoras se han ocupado también de esta cuestión en: "Luxury Goods for Royal Collectors: Exotica, princely gifts and rare animals exchanged between the Iberian Courts and Central Europe in the Renaissance (1560-1612)", en Helmut Trnek y Sabine Haag (eds.): Exotica. Portugals Entdeckungen im Spiegel fürstlicher Kunst- und Wunderkammern der Renaissance. Die Beiträge des am 19. und 20. Mai 2000 vom Kunsthistorischen Museum Wien veranstalteten Symposiums, Jahrbuch des Kunsthistorischen Museums Wien 3, 2001, pp. 1-127; y "Exótica habsburgica. La Casa de Austria 
su cénit con la dinastía borbónica. ${ }^{5}$ Una práctica cuya intensificación a lo largo del siglo XVIII habría sido resultado de la confluencia de diversos factores que contribuyeron a estimularla: el hábito arraigado de todo tipo de consumo suntuario y de prestigio y la fascinación por lo exótico, la enorme afición personal que sentían hacia los animales numerosos miembros de la familia real — la reina Isabel de Farnesio, sus hijos don Carlos y don Luis y casi todos sus nietos-, el incremento del comercio y la apertura de nuevas rutas de navegación, y ese amplio abanico de actitudes hacia la naturaleza característicos de la cultura y de la sensibilidad ilustradas — mezcla de curiosidad intelectual y de afán por aproximarse a ella e imitarla- que abarcaba, además de la afición a la caza o al coleccionismo zoológico, la pasión por la agricultura y la jardinería, el estudio de la botánica y el cultivo de las ciencias naturales.

Es cierto que los monarcas españoles, como observara el embajador francés en Madrid a finales de la centuria, ${ }^{6}$ no habían llegado nunca a tener una ménagerie barroca al estilo de la de Versalles, es decir, un único establecimiento en el que albergar toda su colección y que, a semejanza de un "gabinete de curiosidades vivas", permitiera presentar a los animales separados jerárquicamente de acuerdo a las últimas clasificaciones científicas y proporcionar al tiempo una visión simultánea de todos ellos. ${ }^{7}$ Lo cual no

\footnotetext{
y las colecciones exóticas en el Renacimiento temprano", en Marina Alfonso Mola y Carlos Martínez Shaw (eds.): Oriente en Palacio: tesoros asiáticos en las colecciones reales españolas, Madrid, Patrimonio Nacional, 2003, pp. 27-44. Sin tratar de agotar la bibliografía, noticias dispersas sobre esta cuestión pueden encontrarse también en Jesús Sáenz de Miera: "Ciencia y estética en torno a Felipe II. Imágenes naturalistas de América en El Escorial”, en Reales Sitios, 112, Madrid, 1992, pp. 49-60 y "Lo raro en el Orbe. Objetos de arte y maravillas en el Alcázar de Madrid" en Fernando Checa (ed.): El Real Alcázar de Madrid. Dos siglos de arquitectura y coleccionismo en la corte de los reyes de España, Madrid, Nerea, 1994, pp. 264-307; Bernardo J. García García: "Los regalos de Isabel Clara Eugenia y la corte española. Intimidad, gusto y devoción", en Reales Sitios, 143, Madrid, 2000, pp. 16-27; Annemarie Jordan: "Las dos águilas del Emperador Carlos V. Las colecciones de Juana y María de Austria en la corte de Felipe II", en Luis A. Ribot García (ed.): La monarquía de Felipe II a debate, Madrid, Sociedad Estatal para la Conmemoración de los Centenarios de Felipe II y Carlos V, 2000, pp. 429-472; Pablo Jiménez Díaz: El coleccionismo manierista de los Austrias. Entre Felipe II y Rodolfo II, Sociedad Estatal para la Conmemoración de los Centenarios de Felipe II y Carlos V, Madrid, 2001.

5 Carlos Gómez-Centurión Jiménez: Alhajas para soberanos. Los animales reales en el siglo XVIII, de las leoneras a las mascotas de cámara (en prensa) y el resto de la bibliografía citada en este artículo.

6 Barón de Bourgoing: Tableau de l Espagne Moderne (1797) en José García Mercadal (ed.): Viajes de extranjeros por España y Portugal, Reed. de la Junta de Castilla y León, 1999, t. V, p. 530.

7 Derivado de la voz ménages, usada desde el siglo XIII para referirse a la administración de los gastos domésticos, el término ménagerie se empleaba en el siglo XVI para aludir a la administración de una granja y a sus elementos constitutivos, incluyendo los animales, o al paraje destinado en una casa de campo para alimentar el ganado y las aves de corral. Por extensión, se utilizó en enero de
} 
obsta para que sí tuvieran una auténtica colección zoológica, pues, al fin y al cabo, lo que realmente define la existencia de cualquier colección no es tanto el repertorio de objetos que están presentes en ella o cómo éstos se distribuyen y exponen a la vista de los demás, sino la relación que sus propietarios sostienen con ellos. ${ }^{8}$ Precisamente porque durante el periodo que nos ocupa coleccionar animales exóticos fue en gran medida un gusto personal de los miembros de la familia real y no sólo una forma más de consumo de prestigio, éstos se dispersaron por diferentes palacios y residencias en busca de un mayor y más frecuente contacto físico y visual con ellos, en lugar de ser expuestos todos juntos al público en una única ménagerie. El deseo de disfrutar a menudo de los ejemplares más raros y apreciados, de proporcionarles unas condiciones de subsistencia lo más adecuadas posibles y fomentar su crianza fueron los elementos que se tuvieron en cuenta a la hora de decidir la ubicación de estos "animales de placer" entre los distintos sitios reales, considerando además la época del año en que la Corte residía en cada uno de ellos y sus características territoriales y climatológicas. Los palacios de Aranjuez y de San Ildefonso fueron dos de sus destinos preferentes, pues la familia real pasaba en ellos la primavera y el verano. Ya en Madrid, más que la Casa de Campo o El Pardo —espacios dedicados preferentemente a la actividad cinegética-, su principal albergue sería el Buen Retiro, perpetuando la tradición del siglo anterior. ${ }^{9}$

\section{Alhajas para soberanos}

Muchos más problemas que solventar el destino de estas criaturas planteaba siempre su adquisición. Desde la antigüedad, los animales exóti-

1664 en las Comptes des bâtiments du roi para denominar el lugar que albergaba la colección de animales de Versalles, acepción que adoptó a partir de entonces. Gustave Loisel: Histoire des ménageries, t. II, pp. 102-183; Gérard Mabille: "La Ménagerie de Versailles", en Gazette de Baux Arts, 116, Paris, 1974, pp. 5-36; Louise E. Robbins: Elephant Slaves and Pampered Parrots. Exotic Animals in Eighteenth-Century Paris, Baltimore-London, John Hopkins University Press, 2002, pp. 37-67; Matthew Senior: "The Ménagerie and the Labyrinthe: Animals at Versailles, 1662-1792", en Erica Fudge (ed.): Renaissance Beasts. Of Animals, Humans and Other Wonderful Creatures, UrbanaChicago, University of Illinois Press, 2004, pp. 208-232; Baratay y Hardouin-Fugier: Zoo, pp. 48-52. Sobre su imitación en los territorios germánicos, Bettina Paust: Studien zur barocken Menagerie im deutschsprachigen Raum, Worms, Wernersche Verlagsgesellschaft, 1996.

8 Antonio Urquiza Herrera: Coleccionismo y nobleza. Signos de distinción social en la Andalucía del Renacimiento, Madrid, Marcial Pons, 2007, pp. 19-28.

9 Carlos Gómez-Centurión Jiménez: "Exóticos y feroces. La ménagerie real del Buen Retiro durante el siglo XVIII”, en Goya, 326, Madrid, 2009, pp. 3-25. 
cos habían constituido un valioso obsequio intercambiado por los grandes soberanos como testimonio de su dominio sobre vastos y lejanos territorios. ${ }^{10}$ Durante el siglo XVIII, sin embargo, ocuparon un papel relativamente discreto en la práctica diplomática si los comparamos con las ricas producciones de las manufacturas de lujo, sobre las que había entablada una fortísima rivalidad entre los monarcas europeos. Es cierto que, en ocasiones, llegaron hasta la Corte española algunos animales regalados por Inglaterra, Holanda, Suecia o Portugal, ${ }^{11}$ pero los envíos más numerosos procederían casi exclusivamente de las potencias norteafricanas al tiempo que se firmaban con ellas tratados de alianza y de comercio a lo largo de las últimas décadas de la centuria. ${ }^{12} \mathrm{Y}$ aunque el papel de todos estos obsequios no fuera desdeñable, la principal fuente de aprovisionamiento de animales exóticos para las colecciones reales continuó radicando en los propios territorios extrapeninsulares de la Monarquía: los presidios del norte de África, la América española y Filipinas. Los gobernadores de Ceuta y Orán desempeñaron un papel muy importante en el envío de especies norteafricanas durante la primera mitad del siglo, hasta el extremo de que, vistos los gastos que ocasionaban estas fieras en el Buen Retiro y su escasez de fondos, en 1744 se llegó a proponer que: "sin pedir permiso antes a los reyes por la Secretaría de Estado, no envíen a sus Majestades ningún león, leona, tigre ni otra fiera ni pájaros de África". ${ }^{13}$ No obstante, los animales siguieron llegando y, en 1757, el gobernador de Orán expedía a Madrid una leona que había sido capturada rondando en las inmediaciones de la plaza por estimar que se trataba de "una alhaja propia de un soberano". ${ }^{14}$

Esta consideración de los animales salvajes como "alhajas" propias de los atributos de la majestad real y la creciente afición de los monarcas españoles a coleccionarlos fueron precisamente los motores que mantuvieron vivo su flujo desde América o el archipiélago filipino hasta la Península a partir de la finalización del conflicto sucesorio y hasta el estallido de las guerras napoleónicas. Veamos en qué términos, por ejemplo, le ofrecía a Felipe V el gobernador interino de Filipinas, fray Juan de

10 Liliane Bodson (ed.): Les Animaux exotiques dans les relations internationales, Liège, Université de Liège, 1998.

11 Archivo General de Palacio (AGP), Buen Retiro, 11746/20 y 11752/22; Aranjuez, 14232 y 14233; Fernando VI, 242 al 268, 454 y 469; Carlos III, 142/1; Archivo Histórico Nacional, Estado (AHN), 2557 y 2735; Archivo General de Simancas (AGS), Estado, 6708.

12 AHN, 536, 4350 y 4675.

13 AGP, Buen Retiro, 11740/1.

14 Ibidem, 11752/40. 
Erechederra, un magnífico ejemplar de venado blanco que enviaba como obsequio en 1746:

Señor,

El Rey Salomón se recreaba con una cierva que en la Sagrada Escritura se intitula Cierva del amor, y el que yo por tantos títulos profeso a vuestra Majestad quiere darle este mismo título a un Ciervo todo blanco que se cogió en los montes de la Laguna de Bay de este dominio de vuestra Majestad que, por exquisito y singular, puede ser logre el de ministrar materia a la recreación del Real ánimo de vuestra Majestad, a cuya soberanía lo remito con un collar de oro por mano de vuestro Virrey de Nueva España en muestra de los cordiales deseos de aliviar las fatigas de vuestra Majestad, cuya Católica y Real persona guarde Dios lo que la Cristiandad ha menester. ${ }^{15}$

A pesar de tanta ampulosidad retórica para envolver el regalo, nada sucedía de manera gratuita en los territorios ultramarinos españoles, ni siquiera el envío de ofrendas a sus soberanos. En este caso todo hace sospechar que el obispo pretendía hacerse perdonar la decisión adoptada por el Cabildo de Manila de despachar sin autorización el galeón anual hacia Nueva España, después de que una real cédula real de agosto de 1744 hubiese ordenado interrumpir completamente el comercio con aquel Virreinato por miedo a la presencia de los buques ingleses en los alrededores. ${ }^{16}$ En semejante circunstancia, lo que estaba en juego era la paralización de la vida económica del archipiélago, que dependía por completo de aquel galeón. Las más de las veces, sin embargo, los envíos espontáneos de obsequios a la Corte por parte de los virreyes y gobernadores de Ultramar pretendían simplemente complacer al monarca y obtener de él alguna gracia, casi siempre una promoción en los empleos o un regreso rápido a la Península con un destino más apetecible. Pocas veces constituían una mera y desinteresada demostración de fidelidad a la Corona, como cuando en 1797 el moribundo y arruinado virrey del Río de la Plata dejó encargado que, a su fallecimiento, se remitiesen a España sus mascotas favoritas: "dos pájaros singulares" como regalo para los reyes y un "monito de cabeza blanca" para Godoy, "en memoria del afecto y respeto que conservó hasta el último momento de su vida". ${ }^{17}$ Cualquier cortesano sabía que no convenía nunca quedarse atrás en la feroz carrera por hacerse con el favor real, motivo por el cual la Secretaría de Indias o el presidente de la Casa de la

15 Archivo General de Indias (AGI), Filipinas, 151, Manila, 20 de julio de 1746.

16 M. ${ }^{a}$ Lourdes Díaz-Trechuelo: Filipinas. La gran desconocida (1565-1898), Pamplona, Eunsa, 2001, pp. 206-207.

17 AGI, Estado, 79, 4. 
Contratación, por cuyas manos pasaban cuantos animales llegaban desde América, a menudo pretendían emular a sus colegas del otro lado del Atlántico encargando también por su cuenta aquellos ejemplares que con seguridad agradarían al monarca. ${ }^{18}$ Incluso muchos particulares, al recibir animales exóticos de sus parientes y amigos residentes en las Indias, acababan ofreciéndoselos al soberano, como hiciera en 1787 la marquesa de Sonora con un tapir por parecerle que, siendo un animal tan peculiar, "debe tener ese destino". ${ }^{19} \mathrm{Al}$ fin y al cabo, estos animales resultaban caros de mantener y había pocas esperanzas de que sobrevivieran por mucho tiempo, así es que siempre se obtenía una mayor rentabilidad de ellos utilizándolos como presente.

Sin embargo, el afán coleccionista de los reyes no podía estar a expensas únicamente de las iniciativas de sus súbditos. Y es que, pese a lo conocida que era la inclinación que sentía la familia real hacia los animales exóticos y los favores políticos que se podían obtener satisfaciéndola, esos animales no siempre eran recibidos en la Corte con la abundancia y al ritmo que se deseaban. En tales ocasiones los secretarios de Estado se veían obligados a remitir órdenes para que, a su llegada a puerto, las autoridades se encargaran de comprar cuantos ejemplares trajeran en los navíos los particulares que regresaban de las Indias. ${ }^{20}$ De hecho, si los envíos de animales se intensificaron en la década de 1770 fue sólo después de que la Secretaría de Indias expidiese una circular a todos los virreyes americanos avisando que "cada cual por lo que mira a su virreinato, disponga recoger todos los pájaros más particulares en pluma que allí se críen y los envíe, porque desea verlos el príncipe de Asturias". Esta real orden - que se completó tres años más tarde con otra semejante decretando el envío a la Corte de pelícanos también para el príncipe- ${ }^{21}$ constituyó el principal estímulo que empujó a las autoridades americanas a enviar durante las décadas siguientes toda clase de aves exóticas y de mamíferos raros, tanto para la colección particular del heredero como para la del soberano. Detrás de esta corriente de animales vivos llegados hasta Madrid estuvieron algunas de las personalidades más prominentes de la administración de América y Filipinas de aquel entonces. Hombres como José de Gálvez, el marqués de Croix, Manuel Antonio Flores, Manuel Amat, Simón de Anda o Francisco

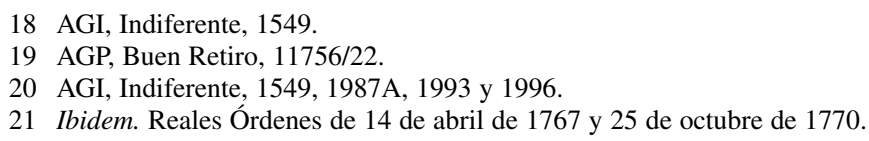


Gil de Taboada, pero también otros innumerables oficiales de menor rango que se vieron implicados en esta actividad, acelerada a partir de 1776 por la inauguración del Gabinete de Historia Natural y por las correspondientes órdenes para que las autoridades americanas colaboraran en el enriquecimiento de sus colecciones. ${ }^{22}$

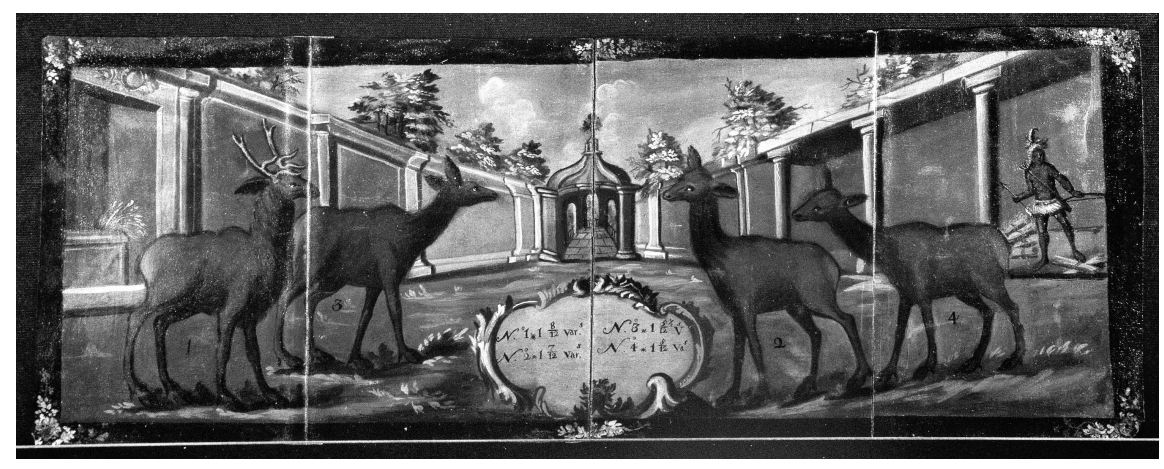

Fig. 1. Dibujo representando los cuatro venados buras adquiridos en Nuevo México por J. B. Ugarte para Carlos III, 1774. AGI, Mapas y Planos, Estampas, n. ${ }^{\circ} 35$.

Las instrucciones dadas por el Gabinete, sin embargo, no incluían el envío de animales vivos para ser estudiados al natural, los cuales continuarían remitiéndose directamente al monarca como regalo para engrosar la ménagerie real. Los naturalistas deberían conformarse con observarlas allí o con conservar sus restos disecados cuando hubieran expirado: las bestias vivas contribuían a glorificar a los príncipes y sólo las muertas resarcirían el ansia de conocimiento de los estudiosos. ${ }^{23}$ Dentro de esta misma lógica, ninguna de las numerosas expediciones científicas que se sucedieron durante la segunda mitad del siglo XVIII —y que volvieron cargadas con centenares de minerales, conchas, semillas y animales y plantas disecadas o en conserva- tenía entre sus objetivos prioritarios regresar con ejempla-

22 Archivo del Museo Nacional de Ciencias Naturales (AMNCN), 59 y AGI, Indiferente, 1544. pp. 19-20.

23 AGP, Buen Retiro, 11756/22 y 11759/46; Gómez-Centurión Jiménez: "Exóticos y feroces",

24 Véanse los intentos infructuosos de Juan de Cuéllar por hacer llegar a España desde Filipinas algunas plantas y pájaros vivos en María Belén Bañas Llanos: Una historia natural de Filipinas: Juan de Cuéllar, 1739?-1801, Barcelona, Ediciones del Serbal, 2000, pp. 260-261. Para el caso de Francia, Robbins: Elephant Slaves, pp. 17-24. 
res vivos, cuya presencia en los convoyes hubiera resultado la mayoría de las veces un estorbo inútil para sus propósitos científicos. ${ }^{24}$ Sería sólo a partir del siglo XIX cuando las nuevas instituciones surgidas de la revolución liberal, como el Muséum d Histoire Naturelle de París, se plantearan entre sus objetivos prioritarios la adquisición de animales vivos con fines de observación y de experimentación. ${ }^{25}$

Entretanto, enviarlos como obsequio para las personas reales constituyó una inversión muchísimo más productiva y menos laboriosa que recopilar las pesadas producciones naturales que demandaba el Gabinete. En términos generales, siempre había buenas razones para tratar de halagar al monarca y satisfacer sus caprichos, pero en algunas circunstancias las necesidades apremiarán más que en otras. Pocos casos están tan bien documentados como el de los venados buras traídos a España en 1776 por Juan Bautista de Ugarte, factor de la renta del tabaco de la ciudad de Durango. ${ }^{26}$ Tras casi diez años desempeñando este cargo, Ugarte se encontraba en una situación financiera muy apurada pues, desde 1768, se venía retrasando en ingresar las cantidades que debía en la tesorería de la Dirección General del Tabaco. Según él, el descubierto en la administración de la renta — por valor de más de treinta y cinco mil pesos — no era a causa de "extravíos o malversación" sino de "quebrantos y contratiempos que acaso no supo prevenir", como fuera el haber tenido que devolver la dote de su primera esposa. Para salir del aprieto, Ugarte aspiraba a conseguir una alcaidía vacante en alguna de las ciudades de Nuevo México, cambiándola por su factoría o, si no era lo bastante rentable, ejerciéndola a través de un teniente. Lógicamente un beneficio como aquel no resultaba fácil de conseguir, de manera que el factor recordó que hacía pocos años el virrey marqués de Croix le había pedido que localizara en los alrededores de su distrito algunos venados buras para enviárselos a Carlos III, que ya poseía otros dos en el Buen Retiro y quería aumentar su colección. ${ }^{27} \mathrm{Ni}$ corto ni perezoso, Ugarte puso manos a la obra para buscar donde fuera los anhelados venados que podían convertirse en su tabla de salvación, de suerte que en el verano de 1774 había conseguido ya reunir cuatro ejemplares jóvenes, domesticados y en condiciones de ser remitidos a España. Sabía, sin embargo, que aquel servicio prestado a tan

25 Richard W. Burkhardt: "Animali vivi per la Ménagerie de Parigi. Istruzioni del Muséum d'Histoire Naturelle", en Maurizio Bosi y Claudio Greppi (eds.): Viaggi e scienza. Le istruzioni scientifiche per $i$ viaggiatori nei secoli XVII-XIX, Firenze, lschki, 2005, pp. 223-241.

26 El expediente se conserva completo en AGI, Guadalajara, 402.

27 AGI, México, 1363 e Indiferente, 1995. 
larga distancia quizás no bastara para hacerse perdonar su mala gestión y obtener además un nuevo cargo más lucrativo, así es que decidió conducir por sí mismo los venados hasta la Corte y ofrecérselos personalmente al monarca. Para obtener el permiso, acompañó su carta de solicitud con un hermoso dibujo de los animales (Fig. 1) que, sin duda, llamaría la atención y despertaría el interés del secretario de Indias, Julián de Arriaga, y de quien en Madrid era su principal protector, José de Gálvez. ${ }^{28}$ Tras un azaroso viaje de casi un año de duración — durante el cual llegó a estar tres meses detenido en México a causa de sus deudas contraídas con la hacienda-, Ugarte pudo al fin presentarse en persona ante el rey y ofrecerle los animales. Carlos III, enterado "de la triste situación de este sujeto y queriendo recompensarle sus dispendios y fatigas", accedió no sólo a resarcirle de los gastos realizados, sino a mantenerle también en su empleo y a concederle la alcaidía mayor de Tehuantepec en cuanto ésta quedara vacante.

\section{Animales feroces, animales curiosos}

Censar con precisión todos los animales que se enviaron desde América y Filipinas con destino a la ménagerie real entre 1701 y 1808 resulta una tarea prácticamente inabordable debido a la dispersión de las fuentes documentales. Sin embargo, las noticias conservadas en el Archivo General de Indias, ${ }^{29}$ combinadas con los fondos del Archivo de Palacio y del Museo Nacional de Ciencias Naturales, nos permiten, al menos, hacernos una idea aproximada de cuáles eran las especies más apreciadas y objeto de un tráfico más frecuente.

Entre los mamíferos, sin ninguna duda, continuaron ocupando un lugar destacado los grandes felinos. Su presencia al lado de los reyes y de los grandes señores se remontaba a la época medieval y pocos animales como ellos, por su fuerza, su ferocidad y el dominio que se suponía que ejercían sobre el resto de las especies, simbolizaban de una forma tan evidente la supremacía del poder regio y los valores guerreros que distinguían al estamento nobiliario. A la admiración por su belleza se añadía el placer de obligarles a luchar con otros animales en sangrientas batallas, para las

28 AGI, Mapas y Planos, Estampas, 35.

29 Aunque se pueden encontrar papeles relativos a este asunto en casi cualquiera de sus secciones, una gran parte de la documentación se encuentra recopilada en AGI, Indiferente, 1544 al 1550 y 1987 al 1999. 
que se edificaron serragli y leoneras en la mayoría de las cortes europeas, como las que hubo en Madrid en la Casa de Campo y en el Buen Retiro. ${ }^{30}$ Precisamente al tiempo que se levantaba esta última, Felipe IV le ordenaba al virrey del Perú que se ocupara de buscar y de remitir hasta la Corte una pareja de las especies más fieras "que hubiese en el distrito de vuestro gobierno", pues había decidido "para la diversión del ánimo y ocupar los ratos que puedo dar al tiempo, después de haber asistido a la continua ocupación y despacho de tantos negocios como dependen del Gobierno de esta Monarquía, tener en parte distinta y separada un circo donde estén encerrados algunos de los animales feroces que naturaleza cría, como son leones, tigres, osos y sus semejantes". ${ }^{31}$ El Retiro continuaría siendo el destino de estos felinos durante el siglo XVIII, a lo largo del cual hemos podido constatar documentalmente la expedición desde tierras americanas de, por lo menos, veinticuatro ejemplares entre 1731 y $1804 .{ }^{32}$ La identificación de cada uno de ellos, sin embargo, plantea graves problemas debido a la informalidad del léxico que se utilizaba en la época para referirse a ellos. Aunque los naturalistas del XVIII —y más los españoles, que conocían bien el Nuevo Mundo- empezaban ya a distinguir con claridad las diferentes especies que poblaban cada continente, los términos que se usaban para designarlos popularmente eran mucho menos precisos. Tal y como reconocía el naturalista Buffon, los franceses -e igual les pasaba a los españoles- solían llamar "tigre" no al auténtico tigre asiático (Panthera tigris), muy rara vez visto en Europa, sino a las panteras y leopardos (Panthera pardus) de África o a los jaguares (Panthera onca) de América. ${ }^{33}$ También la documentación administrativa española seguía empleando los nombres comunes de los felinos ya conocidos de Asia y África para denominar a las especies características del Nuevo Mundo, llamando en ocasiones "leones" a los pumas (Puma concolor) o "tigres" y "leopardos" indis-

30 Jonathan Brown y John H. Elliott: Un palacio para el rey. El Buen Retiro y la corte de Felipe IV, Madrid, Revista de Occidente-Alianza, 1985, pp. 64 y 225-226; Juan Luis Blanco Mozo: Alonso Carbonell (1583-1660), arquitecto del rey y del conde-duque de Olivares, Madrid, Fundación Universitaria Española, 2007, pp. 308-309.

31 Fernando Soler Jardón: "Tres tigres para el Buen Retiro", en Revista de Indias, 28-29, Madrid, 1947, pp. 501-508.

32 AGP, Buen Retiro, 11737/54; 11743/14; 11747/17; 11750/8; 11752/15; 11756/22; 11759/46; Aranjuez, 14242; Carlos III, 156/2. AGI, Indiferente, 1545; 1549; 1988; 1990; 1992; 1996 y 1998.

33 Compendio de la Historia Natural de Buffon, clasificado según el sistema de Linneo por Renato Ricardo Castel, traducido e ilustrado por Pedro Estala, presbítero, Madrid, Villalpando, 1803, t. VIII, p. 109. 
tintamente al jaguar, al ocelote (Leopardus pardalis) y al yaguarundi (Herpailurus yagouaroundi). Pese a que las peleas de fieras acabaron cayendo en desuso entre la sociedad cortesana desde principios de la centuria, ${ }^{34}$ los grandes felinos continuaban siendo apreciados por su belleza y su poder, por lo que los gobernadores americanos solían escoger para enviar a Madrid "tigres" todavía cachorros y, a ser posible, domesticados para "diversión" de los príncipes. Aún así, a finales de la década de 1760 y principios de la siguiente es detectable ya una cierta pérdida de interés hacia estos animales - en beneficio de otras especies más raras-, rechazándose varios ejemplares a su llegada, posiblemente por estar ya repleta la Casa de Fieras del Retiro y ser su manutención tan costosa. ${ }^{35}$

Porque es precisamente a partir de estas mismas fechas cuando comienzan a llegar como obsequio para la familia real animales cada vez más extraños y curiosos por los que los naturalistas y los aficionados sentían una inagotable fascinación. El incremento del interés científico entre las elites, el progreso de las ciencias naturales y la creciente investigación sobre las riquezas originarias del continente americano fueron los motores que estimularon desde entonces el envío a la Península de nuevos y más variados especímenes de los que poblaban el Nuevo Mundo. Ya no eran tan fieros, pero excitaban la curiosidad del público por su aspecto extraño o "monstruoso" y contribuían siempre con su presencia a dar prestigio a la Corona, poniendo de manifiesto su dominio sobre tan extensos y alejados territorios. Después de varias tentativas frustradas, por ejemplo, en julio de 1776 se consiguió que desembarcara en Cádiz sano y salvo un oso hormiguero (Myrmecophaga tridactyla) procedente de Buenos Aires, y que fue ingresado en la Leonera sólo después de que el rey tuviera ocasión de observarle detenidamente "en su mismo Cuarto" y dado orden de retratarle al pintor Rafael Mengs. ${ }^{36}$ Sobrevivió únicamente siete meses, pero, que sepamos, al menos llegaría otro ejemplar vivo en septiembre de 1788 como regalo del gobernador del Consejo de Indias. ${ }^{37}$ Entre estas

34 En Madrid, las noticias más tardías son las que hacen referencia a los gastos ocasionados por los perros de presa que luchaban contra leones para "diversión" del príncipe de Asturias entre 1717 y 1720, AGS, Tribunal Mayor de Cuentas, 3562 y 3563.

35 AGI, Indiferente, 1996, Julián de Arriaga al marqués del Real Tesoro, Aranjuez, 3 de mayo de 1768 y AGI, Indiferente, 1549, Julián de Arriaga al director de la Real Compañía de Caracas, San Lorenzo, 15 de noviembre de 1771.

36 Ana Victoria Mazo Pérez: "El oso hormiguero de su Majestad", en Asclepio. Revista de Historia de la Medicina y de la Ciencia, vol. LVIII, n. ${ }^{\circ}$ 1, Madrid, 2006, pp. 281-294.

37 AGP, Buen Retiro, 11756/ 22. 
especies curiosas se registra también el ingreso en el Retiro de un tapir centroamericano (Tapirus bairdii) en $1787,{ }^{38}$ de un pecarí (Tayassuidae) en 1789 y de tres armadillos mexicanos o "cachicamos" (Dasypus novemcinctus) en $1796 .{ }^{39}$ Otros ejemplares, en cambio, nunca lograrían llegar vivos hasta la Península, como los tepezcuintles (Agouti paca) que se enviaron en varias ocasiones o un gran lagarto vivo capturado en Nueva Granada - probablemente un peligroso caimán negro (Melanosuchus niger) — al que se negó tan siquiera a embarcar el maestre del navío que debía transportarlo. ${ }^{40}$

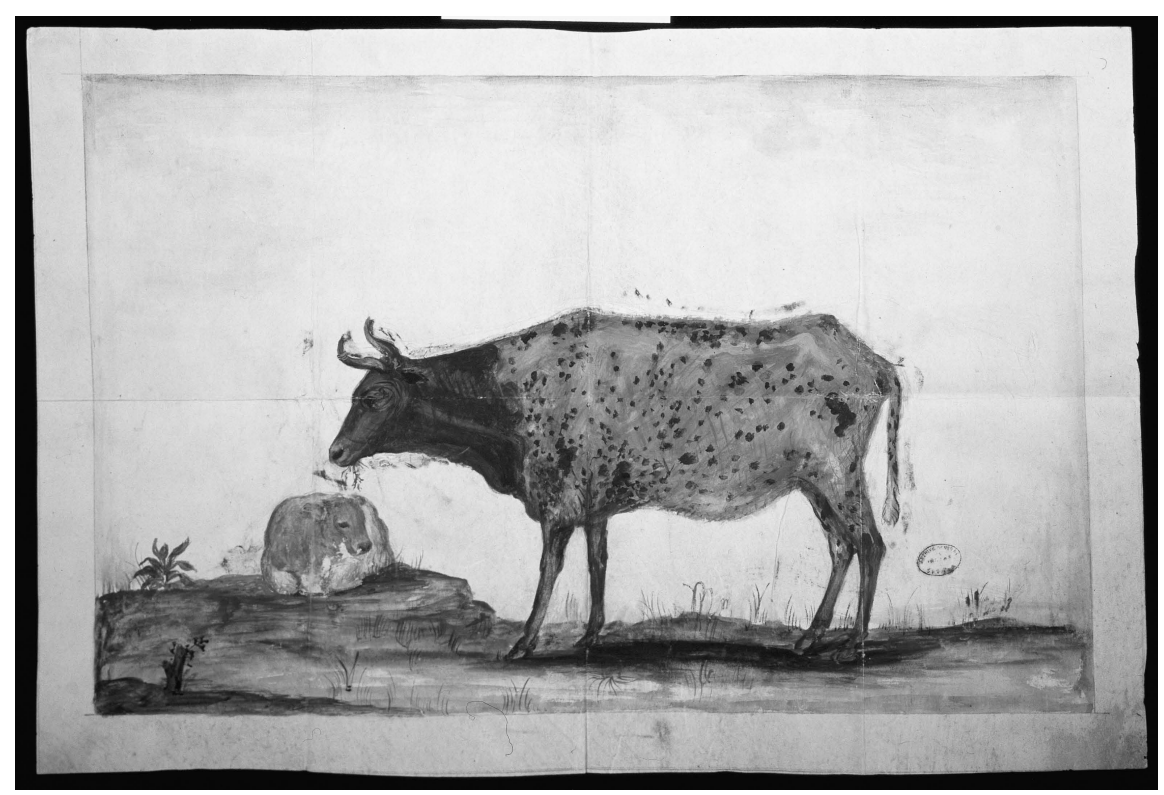

Fig. 2. Dibujo de la vaca sin pelo procedente de Veracruz, 1778, AGI, Mapas y Planos, Estampas, n. ${ }^{\circ} 350$.

38 AGI, Indiferente, 1550 y AGP, Buen Retiro, 11756/ 22. Por estas fechas habría ya en el Gabinete de Historia Natural otros dos ejemplares disecados, macho y hembra, regalo del rey de Portugal. Juan Bautista Bru de Ramón: Colección de láminas que representan los animales y monstruos del Real Gabinete de Historia Natural de Madrid, con una descripción individual de cada uno de ellos, Madrid, Imp. Andrés de Sotos, 1786, t. II, lám. XXXVII.

39 AGI, Lima, 798 y AGP, Buen Retiro, 11759/46.

40 AGI, Lima 798 e Indiferente, 1549. 
Enorme interés para la curiosidad ilustrada de la época tenía también cualquier animal común que pudiera presentar alguna anormalidad anatómica. Casi siempre se trataba de deformidades que resultaban mortales, por lo que el Gabinete de Historia Natural madrileño surtía sus colecciones con dibujos o restos embalsamados de animales monstruosos y de fetos contrahechos que le eran remitidos con cierta asiduidad. Sabemos, sin embargo, que hubo al menos dos de estos animales que llegaron vivos hasta Madrid. En 1779, una curiosa "vaca sin pelo" nacida en una de las haciendas próximas a Veracruz y que el administrador de las rentas reales de aquella ciudad se había cuidado de adquirir, junto a su ternera, para enviárselas al monarca (Fig. 2). ${ }^{41}$ Y, en 1789, una yegua que presentaba una peculiar deformación en los genitales y que fue remitida a la corte por el virrey de Nueva Granada con la pretensión de que era "hermafrodita". ${ }^{42}$

Dado que la mayoría de estos animales iban a parar a la propiedad real como regalos, su selección, por regla general, era algo que quedaba fuera de todo control de la corte. En ocasiones, no obstante, la iniciativa de los virreyes conseguía despertar vivamente el interés de los soberanos, como fue el caso de los venados bura o venados "burros" (Ocodileus hemionus crooki) procedentes de Nueva España y a los que ya hemos aludido. Denominados así por los primeros conquistadores a causa de sus grandes orejas, los buras constituían un preciado trofeo debido a su enorme tamaño y a las dimensiones que alcanzaban sus astas, lo que les convertía en un regalo ideal para un cazador avezado como era Carlos III. Los dos primeros ejemplares fueron enviados por el virrey de México en 1764 y llamaron poderosamente la atención del monarca, a juzgar por el interés que demostró por conservarlos en óptimas condiciones en el Retiro ${ }^{43}$ y por conseguir nuevos ejemplares durante los años siguientes. ${ }^{44}$

Mayores satisfacciones aún le produjeron a Carlos III los animales procedentes del lejano Oriente obtenidos a través de Filipinas. Gracias a su interés por fomentar la navegación española en el Pacífico y a su habilidad para explotar las rivalidades existentes entre los nawabs de la India, el gobernador Simón de Anda fue capaz de conseguir hasta tres ejemplares de elefante asiático (Elephas maximus), una de las más preciadas posesiones

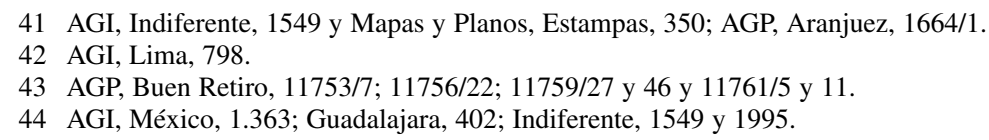


del monarca español. ${ }^{45}$ En 1774 le pudo enviar también a la princesa de Asturias un cargamento de peces chinos o goldfish (Carassius auratus), tan de moda entonces en Europa ${ }^{46} \mathrm{Y}$, sin embargo, aparte de los elefantes, los animales que mayor atracción ejercieron sobre Carlos III fueron los venados enanos de Java (Tragulus javanicus), los cérvidos más pequeños del mundo que le regaló en 1777 el nawab de Carnatic, Mohammed Alí Khan Walajan, y que habitaron durante años en el mismo cuarto del soberano junto a sus demás animales de cámara. La familia real solía recibir como obsequio toda clase de mascotas — sobre todo titíes y pequeños simios—, ${ }^{47}$ pero los ciervos ratón se convirtieron en la gran novedad del palacio madrileño, hasta el extremo de que Carlos III dio la orden de que en adelante todas las naves que llegaran a Cádiz procedentes de Filipinas procurasen traer más ejemplares, rechazando, en cambio, el resto de animales que desde aquel archipiélago le enviaba el gobernador Basco y Vargas para tratar de complacerle "porque no son apreciables para el rey". ${ }^{48}$

\section{Las prodigiosas aves}

Además de los grandes felinos y los cuadrúpedos raros, las aves ocuparon el lugar más sobresaliente en la mayoría de las colecciones zoológicas de la época moderna. Un protagonismo que se fue incrementando con el transcurso del tiempo conforme las peleas de fieras caían en desuso, convirtiéndose a veces en casi los únicos habitantes de las ménageries más modestas, entre otros motivos porque resultaban más fáciles de adquirir y baratas de mantener. A cambio, el continuo descubrimiento de nuevas especies impulsó a coleccionarlas y a buscar incansablemente ejemplares nuevos y cada vez más raros, puesto que su diversidad se consideraba tanto un reflejo fiel del poder creador de la naturaleza como un indicador de la magnificencia de sus dueños. El esplendor de sus formas, la riqueza de

45 Salvador P. Escoto: "Haidar Alí: un intento frustrado de relación comercial entre Mysore y Filipinas, 1773-1779", en Revista Española del Pacífico, n. ${ }^{\circ}$ 10, Madrid, 1999, pp. 45-75; Gabriel Sánchez Espinosa: "Un episodio en la recepción cultural dieciochesca de lo exótico: la llegada del elefante a Madrid en 1773", en Goya, 295-296, Madrid, 2003, pp. 269-286; Ana Victoria Mazo: Los cuatro elefantes del rey Carlos III, Madrid, AMNCN-CSIC, 2008; AHN, Estado, 3403; AGI, Estado, 45 y Filipinas, 390.

46 AGI, Indiferente, 1549; Yi-Fu Tuan: Dominance and Affection. The Making of Pets, New Haven, CN, Yale University Press, 1984, pp. 95-100.

47 AGI, Indiferente, 1987A, 1991, 1549.

48 AGI, Filipinas, 390 y 391; Indiferente, 1549; AGP, Carlos III, 58 a 66. 
sus colores, su melodioso canto, todo en ellas contribuía a que fueran consideradas auténticas obras de arte vivientes, despertando una fascinación que evidencia el creciente nivel de refinamiento alcanzado por las cortes europeas. Poco importaban su forma, su tamaño o su hábitat: aves parlantes como los loros y guacamayos, acuáticas como los pelícanos, grullas, garzas o cormoranes, de plumaje espectacular como las aves del paraíso, criaturas extrañas como los dodos de las islas Mauricio, pequeñas curiosidades como los colibríes, o gigantes como los cóndores, los casuarios y los avestruces. Y junto a ellas, otras especies más domésticas pero importadas también de tierras lejanas, como los pavos reales y los faisanes asiáticos, las gallinas de Guinea o los deliciosos pavos americanos descubiertos por los conquistadores españoles. Acomodadas en grandes pajareras, estanques, corrales o faisaneras, su presencia servía lo mismo para alegrar y dar vistosidad a los jardines que para dar prestigio a sus propietarios o regalar su mesa. ${ }^{49}$ Abundantes, llamativas y más fáciles de transportar que otros animales de mayor tamaño, las aves exóticas inundaron las ciudades portuarias y los palacios reales de Portugal y Castilla a partir de la época de los descubrimientos, erigiéndose en testimonios vivientes de los extensos y lejanos territorios que ambas monarquías controlaban.

A lo largo del siglo XVIII, entre las aves americanas de mayor tamaño las águilas coronadas (Harpyhaliaetus coronatus) y los cóndores reales (Sarcoramphus papa) fueron objeto de frecuentes envíos hacia Madrid, ya que las rapaces y carroñeras constituían los huéspedes tradicionales del piso alto de la Leonera del Retiro. ${ }^{50}$ Otra especie que aparece a menudo mencionada en la documentación es el paují o "pájaro piedra" (Pauxi pau$x i)$, característico del norte de Colombia y de Venezuela, y que los oficiales americanos enviaban a España con cierta frecuencia tanto por su llamativo aspecto como por su deliciosa carne, que comparaban con la del faisán. ${ }^{51}$ Por lo que respecta a las acuáticas, el marqués de Croix intentó remitir a Madrid, en 1770, diez garzas paletas (Ajaia ajaja) y cinco cigüeñas soldado (Jabiru mycteria), pero ninguna de ellas sobrevivió a la travesía. ${ }^{52}$ Mayor fortuna, en cambio, tuvieron la mayoría de las avutardas y gan-

49 Baratay y Hardouin-Fugier: Zoo, págs. 32-37.

50 AGP, Patrimonio, Buen Retiro, $11737 / 54 ; 11751 / 28 ; 11752 / 43 ; 11756 / 22$ y 11759/46. AGI, Indiferente, 1549 y Lima, 798.

51 AGP, Buen Retiro, 11751/28 y 11759/46; AGI, Indiferente, 1549 y Lima, 798.

52 AGI, Indiferente, 1549; Bru, sin embargo, menciona la presencia de una de estas cigüeñas en el Retiro, Colección de láminas, t. I. láms. XXIV y XXV. 
sos silvestres enviados por el intendente de la Luisiana en 1787 y que fueron a parar a la Casa de Campo. ${ }^{53}$

A pesar de que todas estas aves eran recibidas con aceptación en la Corte y contribuían a mantener poblados los aviarios y los estanques reales, las especies por las que las personas reales sentían una mayor predilección eran aquellas que se podían acomodar en el interior del palacio y acompañar a sus dueños en sus desplazamientos estacionales por los reales sitios, convertidas en auténticas mascotas familiares. El viajero inglés William Beckford, que visitó el Palacio Nuevo de Madrid en 1787, no pudo menos que dejar constancia del elevado número de estos pájaros que encontró por todas las habitaciones:

En esta estancia [la alcoba del viejo rey], como en todas las otras que visité, sin excepción, había jaulas de alambre dorado, de distintas formas y tamaños, y en cada una de estas jaulas había un pájaro exótico y curioso, gorjeando como loco, como si estuvieran disputándose un premio de canto. Mezclado con estos pájaros se oía a intervalos el tañido suave de los relojes musicales, que penetraba subrepticiamente en el oído. Ningún otro sonido rompía el silencio general, excepto por cierto, los pasos casi inaudibles de varios viejos criados, cuyas libreas mostraban el corte y la moda reinante en los días de la madre del Rey, Isabel de Farnesio; éstos parecían deslizarse suave y cautelosamente, abrían las jaulas y ofrecían a sus habitantes las golosinas a que todo pájaro culto está acostumbrado. A consecuencia de estas atenciones las avecillas revoloteaban o se agachaban y los criados sonrientes les acariciaban el pico o la cabeza, cosa en que yo les imité..$^{54}$

Las más copiosas solían ser las aves canoras — que disponían en palacio de su propio maestro de música- ${ }^{55} \mathrm{y}$ entre las cuales las americanas, por su exotismo y su belleza, eran sin duda las más apreciadas: el sinsonte o "pájaro cien voces" (Mimus polyglottos), el gorrión de Indias (Melospiza melodia), el cardenal (Cardenalis cardenalis), el pájaro mariposa (Passerina ciris), el azulejo (Passerina cyanea), el turpial (Icterius icterius), etc. Aunque el envío de esta clase de aves se solicitaba periódicamente a las autoridades ultramarinas, ${ }^{56}$ el periodo en el que la familia real pudo disponer de ellas con mayor abundancia fue durante el largo quinquenio que la Corte pasó en Andalucía entre 1729 y 1733, recibién-

53 AGI, Indiferente, 1550.

54 William Beckford: Un inglés en la España de Godoy (Cartas españolas), Madrid, Taurus, 1966, pp. 122-123.

55 AGP, Personal, 857/18; Felipe V, 18; Fernando VI, 246, 248, 249, 255 y 259.

56 AGI, Panamá, 231, 7, 383r.-383v., real cédula dirigida al capitán general de la Provincia de Tierra Firme, Aranjuez, 5 de mayo de 1678. 
dolos a menudo como regalo de las ciudades que visitaban. ${ }^{57}$ Debido a la afición que todos sus miembros sentían hacia ellas, durante las décadas siguientes la presencia de estas aves se trasladó también a las pequeñas Cortes familiares de Italia: don Carlos se las hacía enviar con frecuencia mientras fue rey de las Dos Sicilias y, tras regresar a Madrid, las continuó remitiendo como obsequio a sus hijos a Nápoles y Florencia. ${ }^{58}$ Pero su adquisición no siempre resultaba fácil. Pese a los envíos oficiales y a que los marineros solían traerlas en su viaje de regreso a la Península para ponerlas a la venta, las aves no siempre llegaban cuando se esperaban o se necesitaban. En tales ocasiones era preciso remitir a las autoridades portuarias las correspondientes órdenes para que, en caso de no llegar pájaros consignados para los reyes, se tratasen de comprar a los particulares que estuvieran dispuestos a deshacerse de ellos. ${ }^{59}$ Aún así, a veces no había manera de conseguirlos y en 1767, por ejemplo, fue casi imposible localizar todos los ejemplares que Carlos III necesitaba para enviarlos como regalo al rey de Marruecos. ${ }^{60}$

Además de las aves canoras, las otras mascotas más apreciadas eran sin duda los papagayos (Psittacidae). Identificados rápidamente con los viajes de exploración ultramarinos y con las tierras recién descubiertas, sus especies más llamativas — grises africanos, periquitos, amazonas y guacamayos - se convirtieron en valiosos objetos de lujo, codiciados en todas las Cortes europeas. ${ }^{61}$ En España, la afición a los papagayos se mantuvo intacta durante todo el siglo XVIII, de manera que aparecen citados de forma constante en la documentación de palacio, desde las primeras cuentas relativas a los "pájaros y papagayos del Real Cuarto" de María Gabriela de Saboya, hasta la última referente a los dos loros que Carlos IV tenía consigo en el palacio de Aranjuez al tiempo de su abdicación. ${ }^{62}$ Aún así, su presencia fuera de los grandes centros comerciales andaluces y de Madrid no

57 AGI, Indiferente, 1987A y AGP, Felipe V, 172 y 294/2.

58 AGI, Indiferente, 1990; AGP, Fernando VI, 105 y Carlos III, 92/2.

59 AGI, Indiferente, 1549 y 1993; AGP, Carlos III, 141/1.

60 AHN, Estado, 4308 y 4350/2 y AGI, Indiferente, 1.996.

61 Renate Pieper: "Papageien und Bezoarsteine. Gesandte als Vermittler von Exotica und Luxuserzeugnissen im Zeitalter Philips II", en Friedrich Edelmayer (ed.): Hispania-Austria II. Die Epoche Philipps II (1556-1598), Múnich, Oldenbourg, 1999, pp. 215-224 y "Papagayos americanos, mediadores culturales entre dos mundos", en Eddy Stols, Werner Thomas y Johan Verberckmoes (eds.): Naturalia, Mirablia \& Monstrosa en los Imperios Ibéricos (siglos XV-XIX), Leuven, Leuven University Press, 2006, pp. 123-134; Bruce T. Boehrer: Parrot Culture. Our 2500-Year-Long Fascination with the World s Most Talkative Bird, Philadelphia, University of Pensylvania Press, 2004.

62 AGP, Reinado, Felipe V, 255 y Carlos IV-Casa, 170/1. 
era demasiado corriente. Al marqués de Langle le había llamado la atención, nada más entrar en la Corte, haber visto "titíes, monas, cacatúas, loros en casi todas las ventanas", ${ }^{63}$ pero al corresponsal en Bilbao del director del Gabinete de Historia Natural le parecía imposible, en 1774, encontrar en aquel puerto un guacamayo para comprar, ya que únicamente se había visto uno hacía años en Bermeo "en poder de un caballero particular, traído por un cuñado suyo de un viaje que hizo al Orinoco", y sólo los marineros que volvían de Terranova o de las Antillas traían de vez en cuando titíes o papagayos más corrientes. ${ }^{64}$

Los loros de todas clases continuaban fascinando por su aspecto llamativo y multicolor - debido al cual aparecen profusamente representados en los interiores palaciegos, desde el Salón del Trono del Palacio Nuevo hasta el Gabinete de Porcelana de Aranjuez-, pero su presencia física en las habitaciones reales se debía, antes que nada, a su éxito como animales de compañía. Como mascotas, los loros pueden resultar auténticamente divertidos. Por lo ruidosos, sucios y traviesos que llegan a ser quizás no fuera el animal que más fácilmente seamos capaces de imaginar habitando en la solemnidad de un palacio. Pero, a menudo, se nos olvida que su inteligencia, su inagotable sentido del humor, su picardía y su malicia podían proporcionar a su entorno justamente el tipo de desahogo que un ambiente tan jerarquizado y protocolario como el cortesano más necesitaba. Su función, en cierta forma, recuerda a la que los enanos y bufones tuvieron en la Corte de los Austrias, consistiendo su gracia en violar los rígidos usos de la sociedad estamental y de la etiqueta palaciega, pues sólo a ellos se les permitía hacer burla de los cortesanos o decir con libertad las verdades al rey. ${ }^{65}$ Asociación entre la "lengua libre" de los bufones y la locuacidad de los papagayos que queda perfectamente plasmada en algunos de los últimos retratos que se pintaron en la corte española de sus enanos - por Juan Carreño o Michel-Ange Houasse - acompañados por cacatúas y papagayos. Precisamente porque su función fundamental era entretener, se valoraba más que nada que supieran hablar bien. ${ }^{66}$ Cuando don Carlos le escribió a sus padres para agradecerles unos periquitos que le habían enviado a

63 Jean Marie Jérôme Fleuriot: Viaje de Fígaro a España (1784), en José García Mercadal (ed.): Viajes de extranjeros, t. V, p. 805.

64 AMNCN, 55.

65 Fernando Bouza: Locos, enanos y hombres de placer en la Corte de los Austrias, Madrid, Temas de Hoy, 1991.

66 Véase el discurso que era capaz de pronunciar una cotorra regalada al infante don Felipe en 1726, AGP, Felipe V, 17. 
Italia, no olvidó precisar "que hablan mucho", ${ }^{67}$ mientras, que el gobernador de Cartagena de Indias se disculpaba ante el príncipe de Asturias porque el único loro que había encontrado para enviarle resultaba "muy apreciable por su pinta", pero hablaba "muy poco español por haber corto tiempo que lo trajeron de los indios bárbaros" ${ }^{68}$ Para excitar su charlatanería - y siguiendo un antiguo consejo de Aristóteles y Plinio- a los papagayos se les solía emborrachar sirviéndoseles todas las tardes "sopas de vino con pan" para merendar. ${ }^{69}$

\section{Exóticos pero útiles}

Una de las cuestiones que más hicieron especular a los naturalistas del siglo XVIII fue la viabilidad de importar y aclimatar en Europa especies domésticas o semidomésticas provenientes de otros continentes, no ya como curiosidad exótica o mero divertimento, sino con fines estrictamente utilitarios, pudiendo representar alguna mejora en los rendimientos ganaderos o en la producción de materias primas para la industria. Pedro Estala, en su edición de la Historia Natural de Buffon, se lamentaba de que no se hubiera llevado a cabo en España una política más ambiciosa y de más amplias miras a este respecto con la fauna originaria de los territorios americanos:

A la verdad, los españoles hemos tenido más cuidado en propagar en América nuestros ganados que en traer de allá los que pudieran ser más útiles a nuestra economía rural y a nuestra industria. En lugar del ganado vacuno, lanar, caballar, etc. de que hemos poblado aquellas vastas regiones, nos hemos contentado con traer monos, papagayos y otras aves de hermoso plumaje, de suerte que aquellos naturales se desquitan con muchas ventajas de lo engañados que fueron en sus primeros cambios con los europeos, cuando daban sus frutos y metales preciosos por pedazos de vidrio y cuentas de abalorio. En lugar de guacamayos y titís deberíamos haber traído sus vicuñas, alpacas, llamas, guanacos, cíbolos, etc. para compensar en algún modo las incomparables riquezas que debe el nuevo mundo a España en gente, ganados y semillas. $^{70}$

67 Jesús Urrea (ed.): Carlos III en Italia, 1731-1759. Inventario de un monarca español, Madrid, Museo del Prado, 1989, p. 45.

68 AGI, Indiferente, 1549. Fernando Morillo Velarde a Julián de Arriaga, Cartagena de Indias, 31 de octubre de 1768.

69 AGP, Reinados, Fernando VI, 469.

70 Compendio de la Historia Natural, t. XIII, 1804, pp. 175-177. 
Las posibilidades materiales de llevar a cabo este tipo de empresas a gran escala eran, sin embargo, muy reducidas pues, además del gigantesco esfuerzo humano y de la enorme inversión que requerían, existía siempre el riesgo de que los animales no llegaran vivos a su destino o no se aclimataran a su nuevo hábitat. Debido a ello, los contados experimentos que se realizaron en este terreno estuvieron siempre limitados al ámbito de la iniciativa de la Corona - la mayoría auspiciados durante el reinado de Carlos III-, e íntimamente relacionados con las transformaciones que se produjeron durante aquellos años en la configuración territorial de los reales sitios. Pero lo mismo que las explotaciones agrícolas modelo, la llegada de estos animales no llegó a tener jamás ningún impacto económico y los pocos ejemplares que sobrevivieron al viaje acabaron siendo considerados, antes que nada, como parte de las colecciones zoológicas reales.

A medio camino entre la curiosidad viviente y el animal útil puede considerarse la famosa hembra de bisonte americano (Bison bison) enviada desde México en 1770 por el virrey de Nueva España, como regalo para Carlos III. Por su dimensión y su bravura se trataba de un animal que pocas veces había viajado hasta Europa, aunque el conde de Buffon recordaba haber visto un ejemplar capturado en América del Norte, criado en Holanda y comprado después por un empresario suizo que lo llevaba de pueblo en pueblo exhibiéndolo "en una gran jaula de la cual no salía, y aún estaba atado a ella por la cabeza con cuatro cordeles que se la tenían muy sujeta". ${ }^{71}$ Por el contrario, la cíbola que llegó a Aranjuez el 11 de octubre de 1770 podía considerarse un animal único pues era completamente mansa. Formaba parte de una pareja de bisontes, macho y hembra, que habían sido criados a mano desde pequeños por un nativo mexicano y de cuya existencia tuvo noticia el marqués de Croix, decidiendo enviárselos al rey como regalo: "por haberme parecido dignos de algún aprecio en ese Reino, mayormente cuando su mansedumbre es tal que hasta mi recámara han entrado sin la menor violencia siguiendo al hombre que los cuida". Embarcados en Veracruz en el mes de abril y llegados a Cádiz a finales del mes de julio, los animales hicieron toda la travesía suspendidos por un arnés en las bodegas del barco, acompañados por su antiguo dueño que se ocupaba de atenderlos. A pesar de sus cuidados, los animales se encontraban muy débiles al desembarcar en la Península y el macho murió de agotamiento en Córdoba, llegando únicamente la hembra sana y salva hasta Aranjuez. ${ }^{72}$ Allí se la instaló

71 Ibidem, p. 131. 
junto al rebaño de búfalos que se criaban en Villamejor, donde vivió apaciblemente hasta su muerte, acaecida en julio de $1774 .{ }^{73}$ Su presencia en el real sitio atrajo a naturalistas y curiosos, quienes llamaron la atención del monarca y de sus ministros acerca de las posibilidades que podría tener introducir un animal como aquel en España, ya que era más fuerte que el buey común y su carne mucho más sabrosa, además de la ventaja añadida que brindaba su lana, llegándose a barajar durante el gobierno virreinal de Martín de Mayorga la posibilidad de enviar todo un rebaño de bisontes americanos con los que iniciar su cría en la Península. ${ }^{74}$

Los principales esfuerzos en esta dirección, sin embargo, se orientaron a implantar en los sitios reales la cría de aquellas especies americanas cuyo pelo podía fomentar la producción de paños finos, en particular vicuñas y guanacos con cuya lana se empezó a experimentar en la Real Fábrica de Guadalajara a finales de la década de $1760 .^{75}$ A pesar de que para la provisión de lana que necesitaba esa fábrica se acordó en un principio recurrir a la importación, no por ello se renunció al proyecto de aclimatar y criar en España los camélidos americanos. La lana más apreciada era la de vicuña (Vicugna vicugna), pero su traslado era también el que planteaba mayores problemas. Al contrario que las llamas (Lama glana) y los guanacos (Lama guanicoe), en el siglo XVIII las vicuñas vivían únicamente en estado salvaje y apenas se tenía noticia de la existencia de algunos ejemplares en cautividad, motivo por el cual los naturalistas de la época no podían sino especular acerca de sus posibilidades reales de domesticación. Se cazaban a millares todos los años en el Virreinato del Perú para hacerse con su pelo, una gran parte del cual - hasta alcanzar las dos mil arrobas anuales en ocasiones- era remitido a España para su posterior venta y comercialización en el continente. Semejantes matanzas sólo contribuyeron a propagar el miedo sobre su extinción, pareciendo cada vez más urgente la necesidad de traerlas a Europa. El Semanario de agricultura y artes dirigido a los párrocos creía que se podrían aclimatar sin dificultad en Sierra Nevada, el Moncayo o los Pirineos y que "los que nos trajesen esta verdadera riqueza de América y la connaturalizasen en la Península, harían venerar y bendecir su nombre y fama hasta los siglos más remotos, y con mucha más razón

72 AGI, Indiferente, 1549.

73 AGP, Aranjuez, 14228 y 1523/1.

74 Compendio de la Historia Natural, t. XIII, 1804, pp. 175-177.

75 Agustín González Enciso: Estado e industria en el siglo XVIII: la Fábrica de Guadalajara, Madrid, Fundación Universitaria Española, 1980, pp. 575-576 y 609. 
que los descubridores de las minas de preciosos metales". ${ }^{76}$ Pero capturar vivo un animal tan salvaje y asustadizo y hacerle cruzar el Atlántico no era tarea fácil. Al revés que otros camélidos, las vicuñas necesitan beber agua fresca y abundante todos los días, un bien precioso y casi siempre escaso en los navíos que realizaban la Carrera de Indias. Además resisten muy mal el calor, tal y como le explicaba en 1770 el máximo gobernante del Perú al secretario de Estado, de quien había recibido una instrucción sobre las precauciones "conducentes a preparar la naturaleza de estos animales al aguante de los calores que se experimentan en la navegación dentro de los trópicos". El virrey dudaba mucho de que tales prevenciones pudieran dar resultado alguno - "por su natural temperamento inavenible con el calor de la zona tórrida"-, quedando constancia de numerosos intentos infructuosos por hacer llegar vicuñas vivas hasta España desde el reinado de Felipe II. ${ }^{77}$ Pese a ello, Manuel Amat procuró complacer a su soberano enviando algunas vicuñas desde el Perú, pero se trató siempre de ejemplares sueltos. ${ }^{78}$ La experiencia volvería a repetirse a comienzos de la década de 1790 y, en esta ocasión, de un total de doce vicuñas enviadas desde Perú, solamente consiguió sobrevivir una, remitida como mera curiosidad zoológica a los jardines del palacio del Buen Retiro. ${ }^{79}$

Una operación parecida se intentó con la lana de los guanacos chilenos (Lama guanicoe), aprobada por la Secretaría de Indias en 1774, para proveer también a la Real Fábrica de Guadalajara. ${ }^{80}$ Llegados en 1778, fueron a parar a la Casa de Vacas de Aranjuez, donde el embajador francés Bourgoing recordaba haberlos visto "pacer y saltar en un prado contiguo [...] como si estuvieran en su país natal", pero sobre cuya reproducción no ha quedado noticia alguna. ${ }^{81}$

A finales del siglo, después de innumerables descalabros, es posible detectar ya un considerable cansancio entre las autoridades españolas frente a esta clase de empresas, condenadas desde el principio al fracaso pese a que tanto entusiasmaban a Carlos III. Resulta sumamente significativa la

76 Compendio de la Historia Natural, t. XI, 1804, pp. 251-297.

77 AGI, Lima, 652/ 24 y Gaspar de Escalona Agüero: Gazofilacio real del Perú. Tratado financiero del coloniaje (1647), ed. castellana., La Paz, Editorial del Estado, 1941, p. 264.

78 AGI, Lima, 651/59 y 652/ 182 y AGP, Casa de Campo, 9 y 10. Con anterioridad al reinado de Carlos III sólo se tiene noticia de la llegada al Retiro de una vicuña en 1756, AGP, Buen Retiro, $11752 / 15$.

79 AGP, Buen Retiro, 11759/46 y 11763/ 13.

80 AGS, Secretaría de Hacienda, 771. Noticias sobre otros envíos malogrados de guanacos en AGI, Indiferente, 1549 y 1996.

81 Barón de Bourgoing: Tableau de l Espagne Moderne, p. 530. 
anotación realizada en 1784 por José de Gálvez, entonces secretario de Indias, al margen de una carta del virrey del Río de la Plata en la que le comunicaba el envío a Cádiz de un cargamento de seis avestruces (Rhea americana) con los que el monarca pretendía fomentar en España el obraje de adornos con sus plumas. En ella Gálvez ordenaba lacónicamente su archivo y añadía a continuación: "a ver si les sucede lo que a los guanacos y nos ahorramos este trabajo". ${ }^{2}$

\section{Mercancías vivas}

Y es que si los animales procedentes de América — sobre todo los de mayor tamaño- no alcanzaron una presencia importante en las colecciones reales, ello se debió fundamentalmente a sus escasas posibilidades de sobrevivir a un viaje tan largo y penoso. Porque se tenían pocas esperanzas de que estas criaturas llegasen vivas hasta su destino, sus remitentes solían hacerlas acompañar de dibujos y retratos que pudieran sustituirlas en caso de defunción, como al oso hormiguero enviado desde Maracaibo en 1751 (Fig. 3) o a un "papagayo especial [...] con dos retratos de él" regalado al infante don Luis por el marqués de Sobremonte en $1764 .^{83}$

Si ya en trayectos más cortos y con especies domesticadas el transporte de animales vivos representaba siempre una empresa difícil, en el caso de ejemplares exóticos procedentes de América las dificultades se multiplicaban hasta el infinito. El viaje de regreso hasta la Península resultaba incomparablemente más largo y problemático que el de ida, a causa de lo cual el itinerario desde Veracruz a Cádiz — haciendo escala en La Habana y en las Azores - duraba un promedio de ciento dieciocho días, con un mínimo de ochenta y dos y un máximo de doscientos setenta. ${ }^{84}$ Los plazos para la remisión de las mercancías, no obstante, podían alargarse muchísimos más meses, incluso años, desde su adquisición en algún punto de la geografía americana hasta su despacho a España, lo que constituía un grave inconveniente en el caso de animales vivos. Cuatro jaguares enviados por el virrey del Perú a Felipe IV, en 1635, antes de embarcar hacia Cádiz tuvieron que realizar el trayecto Guayaquil/Callao/Panamá/Cruces/Porto-

82 AGI, Indiferente, 1550, El marqués de Loreto a José Gálvez, Buenos Aires, 30 de julio de 1784.

83 AGI, Indiferente, 1991 y 1995; Mapas y Planos, Estampas, 159.

84 Antonio García-Baquero González: Cádiz y el Atlántico, 1717-1778. El comercio colonial español bajo el monopolio gaditano, 2 ts., Sevilla, CSIC, 1988, t. I, pp. 263-287. 
belo/La Habana, lo que provocó la muerte de uno de los ejemplares durante el camino y que la tercera etapa fuera necesario realizarla a pie cargando las pesadas jaulas a hombros de cuarenta y ocho esclavos negros. ${ }^{85}$ Incluso una vez que habían llegado al puerto de salida, los animales podían tener que esperar interminables semanas para iniciar la travesía debido al retraso de las flotas de Indias o a que no siempre era posible encontrar un navío disponible para su flete.

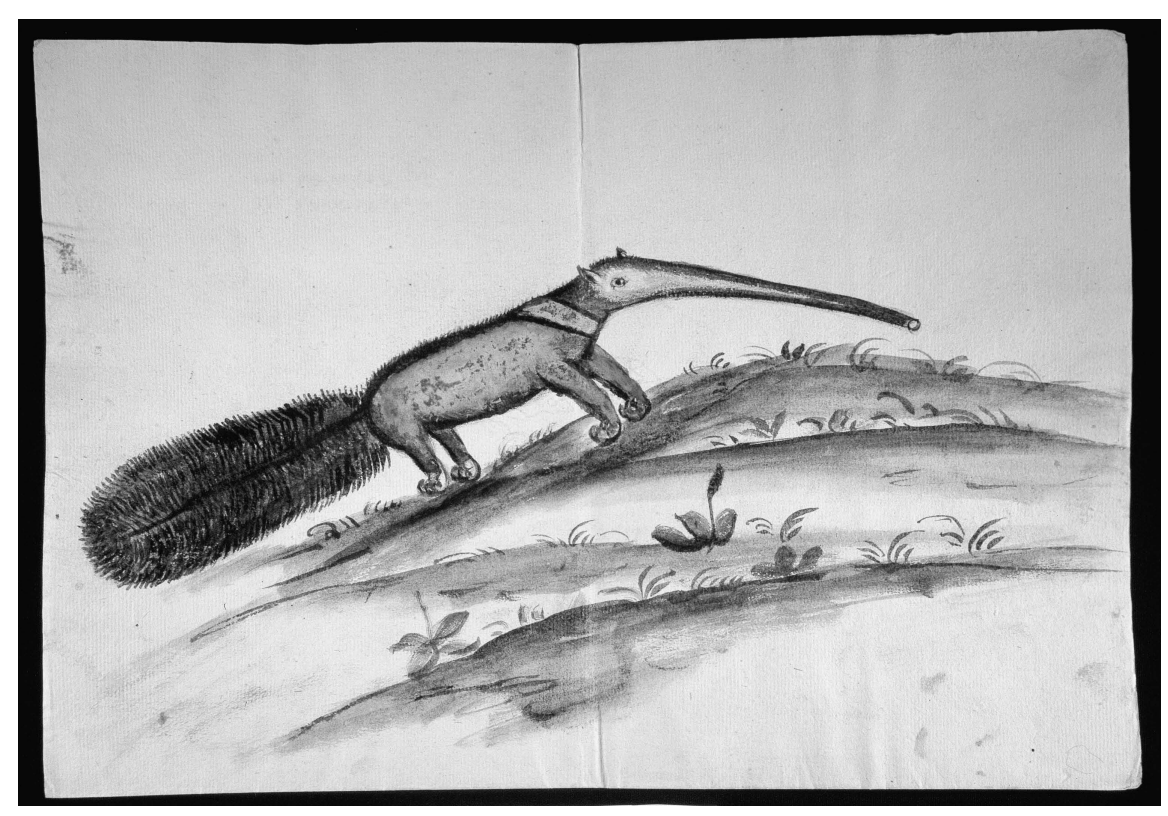

Fig. 3. Dibujo de un oso hormiguero procedente de Maracaibo, 1751, AGI, Mapas y Planos, Estampas, n. ${ }^{\circ} 159$.

Durante la segunda mitad del siglo XVIII, la comunicación entre España y América se hizo más ágil y rápida y la política comercial operó bajo el signo de la liberalización. El recurso cada vez más frecuente al navío suelto, la constitución de compañías privilegiadas y la habilitación de numerosos puertos peninsulares para comerciar directamente con las colonias fueron logros importantes en este terreno. A pesar de ello, hubo tam-

85 Soler Jardón: “Tres tigres”, pp. 504-506. 
bién periodos cada vez más prolongados de interrupción de las comunicaciones y de la navegación a causa de la extensión al Atlántico de la mayoría de los conflictos continentales. Sin llegar a motivos tan graves, a veces había que retrasar los embarques simplemente porque no era la estación del año adecuada. En octubre de 1768, después de meses de esfuerzo, el gobernador de Maracaibo logró por fin reunir algunos pájaros para remitir al príncipe de Asturias, pero el capitán del único navío disponible, perteneciente a la Real Compañía Guipuzcoana, se negó a hacerse cargo de las aves porque arribaría a San Sebastián en pleno invierno y "sería imposible que llegase pájaro vivo" ${ }^{86}$ Demoras de este tipo no hacían sino multiplicar las bajas antes de que los animales pudiesen siquiera embarcar.

Con todo, el periodo más devastador para su supervivencia era la travesía del Atlántico, sin que las mejoras en la navegación variaran sustancialmente esta situación a lo largo del siglo XVIII; habría que esperar a la aparición del motor a vapor y del casco de acero durante la centuria siguiente para que el transporte de animales vivos a larga distancia tuviera unas ciertas garantías de éxito. Instalar a los animales a bordo y embarcar toda la comida y el agua necesarias para su manutención durante meses constituía por sí mismo un problema de primera magnitud en unos navíos en los que la falta de espacio disponible era un problema crónico. Cuando en 1770 el virrey marqués de Croix envió desde México uno de los cargamentos de animales más importantes que se habían hecho hasta entonces - compuesto por una pareja de cíbolos, un cachorro de tigre, un águila, un tepezcuintle, diez pájaros flamencos y cinco cigüeñas sargento- se redactaron unas detalladas instrucciones sobre cómo instalarlos y alimentarlos en el navío de guerra España ${ }^{87}$ Lo mismo que solía hacerse con los caballos o el ganado vacuno, los cíbolos debían realizar todo el viaje suspendidos por cinchas y ser desembarcados también con ellas. Los demás irían instalados en jaulas cubiertas con lonas o pieles para proteger a sus habitantes de las peores inclemencias del viaje. A pesar de lo que pueda parecer, una jaula no era siempre el lugar más seguro para navegar y, de once perdices que fueron enviadas desde Cartagena de Indias en 1769, sólo una consiguió llegar viva hasta Cádiz "por efectos del continuo desasosiego que estas aves han tenido en la navegación, de que ha resultado a las restantes 1768

86 AGI, Indiferente, 1549, Alonso del Río a Julián de Arriaga, Maracaibo, 4 de octubre de

87 Ibidem. El marqués de Croix a Julián de Arriaga, México 1 de abril de 1770 y Pedro A. de Cossío a Francisco Estorgo, Veracruz, 14 de abril de 1770. 
morirse rompiéndose las cabezas contra las jaulas". ${ }^{88}$ Aun enjaulados, había animales que no parecía posible controlar dentro de un buque y, como ya vimos, el maestre de La Soledad se negó a traer hasta España un caimán negro que venía acomodado en un cajón de casi cuatro metros de largo.

Su alimentación a bordo constituía otro grave inconveniente, aunque variaba en función de qué especie se tratara. De los veinte ejemplares embarcados por el marqués de Croix en Veracruz, los herbívoros eran los que planteaban menos problemas: los dos cíbolos podían comer maíz, cebada y forraje - fáciles de conservar durante la travesía-, y el tepezcuintle maíz, pan "o cualquier otra cosa que se le da". El grado de dificultad se incrementaba con los flamencos y las cigüeñas sargentos, pues deberían mantenerse con carne o pescado siempre y cuando no estuvieran en salazón: "pues está observado que así mueren luego". Como alternativa, durante la navegación se les podía proporcionar "sobras de la olla, tripas de terneros, carneros y de gallinas y también bizcocho remojado echándoselo en los bebederos". Con semejante régimen, excusa decir que murieron trece de los quince ejemplares que viajaban en el España. Por inadecuación de la dieta debió de fallecer también el oso hormiguero remitido desde Maracaibo en 1751 - otro espécimen francamente difícil de alimentar en alta mar-, al que se daba de comer la sangre de las reses que se mataban durante la travesía o "un gigote muy menudo de vez en cuando". ${ }^{89}$ Lo que debía comer un carnívoro salvaje no ofrecía dudas, pero la carne fresca se agotaba al poco de zarpar y sólo después de una escala era posible volver a subir a bordo aves de corral, ovejas o cerdos. Al cachorro de tigre y al águila enviados por el marqués de Croix podía bastarles con comer algunos desperdicios de todo este ganado, pero las necesidades se incrementaban al tratarse de un gran felino o de otro animal de mayor tamaño. Como alimento de los tres jaguares enviados a Felipe IV en 1635, por ejemplo, hubo que embarcar treinta cerdos - y seis fanegas de maíz para mantener a la piara- que no resultaron suficientes, de manera que su conductor se vio en la necesidad de comprar a bordo otros tres cerdos y un carnero. ${ }^{90} \mathrm{La}$ escasez de alimentos y el racionamiento en los buques se agudizaban cuando la travesía se alargaba y amenazaba el fantasma del hambre. En estas circunstan-

88 Ibidem. El marqués del Real Tesoro a Julián de Arriaga, Cádiz, 29 de diciembre de 1769.

89 Enrique Martínez Ruiz y Magdalena Pi Corrales (eds.): La Casa de Borbón: ciència i tècnica a l Espanya illustrada, Valencia, Consellería de Cultura, Educació i Esport, 2006, p. 275.

90 Soler Jardón: “Tres tigres”, p. 506. 
cias quizás muy pocos se hubieran atrevido a sacrificar un animal que perteneciera al rey, pero los monos y pájaros que solían llevar los marineros como mascotas o para vender podían convertirse fácilmente en comida de la tripulación en un momento de emergencia.. ${ }^{91}$

Idéntico problema existía con el agua potable, que se alteraba muy rápido en las barricas de madera. Siempre racionada, su falta era uno de los motivos de queja más frecuentes y los marinos ingleses utilizaban el término horse latitudes para referirse a aquellos puntos de la travesía en los que había que comenzar a arrojar el ganado por la borda si surgía la necesidad de ahorrar las reservas de agua para la tripulación. ${ }^{92}$ En concreto, para que bebieran los tres jaguares de Felipe IV fue necesario embarcar una pipa de casi quinientos litros de agua por cada uno. Nada especificaban las instrucciones del marqués de Croix respecto a la ración diaria de sus animales, pero sí que los flamencos y las cigüeñas debían estar siempre "bien proveídos de agua, por ser estos pájaros criados en ciénagas y a orillas de lagunas". Tampoco se les podía escasear la bebida a los dos cíbolos - "porque son de temperamento frío"-, siendo además necesario remojarlos a diario, aunque fuese con agua salada.

En un espacio tan angosto y en el que los requerimientos mínimos para su supervivencia no siempre estaban asegurados, la tasa de mortalidad de los animales era altísima. Si bien estos envíos no suelen estar suficientemente documentados como para ofrecer datos estadísticos, bastan algunos ejemplos. De los veinte ejemplares remitidos desde Nueva España en 1770, sólo cinco —un 25\% - llegaron vivos a Cádiz: los dos cíbolos, el cachorro de tigre y dos flamencos, de los cuales únicamente consiguieron alcanzar Madrid la hembra de cíbolo y el tigrecito. ${ }^{93}$ Todavía más numeroso fue el envío realizado desde Cartagena de Indias por el virrey de Nueva Granada en la primavera de 1789, compuesto por treinta y dos aves de diferentes especies y quince mamíferos de todos los tamaños: después de una travesía de sesenta y dos días - "en un viaje bastante incómodo por calmas y vientos contrarios" - únicamente desembarcaron con vida en La Coruña nueve pájaros, dos pecaríes, un mono y un caballo, poco más del $27 \%$ de los que habían zarpado. ${ }^{94}$

91 Robbins: Elephant Slaves, p. 9-36.

92 Jean Pierre Digard: "Un aspect méconnu de 1 histoire de 1 Amérique: la domestication des animaux", en L Homme, n. ${ }^{\circ} 122-124$, París, 1992, pp. 253-270.

93 AGI, Indiferente, 1549, Francisco J. Estorgo a Julián de Arriaga, Cádiz, 16 de agosto de 1770.

94 AGI, Lima, 798. 
El problema de la distancia y, por tanto, de la previsible mortandad de los animales se acentuaba aún más cuando procedían de Filipinas. Los galeones de la carrera de Acapulco, las naos que todos los años a primeros de julio salían de Manila cargadas a rebosar de mercancías procedentes de Oriente, tardaban seis meses en llegar a su punto de destino impulsados por el monzón de verano. Desde Acapulco había que alcanzar la ciudad de México por un endemoniado camino de herradura para, finalmente, trasladar al puerto de Veracruz las mercancías que se deseaban despachar hasta España. ${ }^{95}$ Evidentemente, enviar un animal vivo con aquellas condiciones desde Manila hasta Madrid constituía toda una hazaña, como fue el caso del venado blanco regalado a Felipe $\mathrm{V}$ por el obispo Arrechederra, que salió de Manila en julio de 1746 y llegó al Retiro en octubre de 1747. ${ }^{96} \mathrm{La}$ situación comenzó a cambiar favorablemente a partir de 1765, cuando la Corona decidió patrocinar los viajes comerciales directos entre Cádiz y Manila en navíos de la Real Armada, a través de la ruta del Cabo de Buena Esperanza, reduciendo el itinerario anterior a únicamente seis meses de viaje. ${ }^{97}$ Gracias a esta novedad fue como Simón de Anda y sus sucesores pudieron enviar hasta Madrid los elefantes indios y los demás animales que ya hemos mencionado, aunque debido a la duración y a los avatares de la ruta las tasas de mortalidad fueran muy semejantes a las de la travesía del Atlántico.

\section{El fin de una época}

A finales del siglo XVIII, el prestigio de que hasta entonces habían gozado las colecciones zoológicas reales comenzó a declinar. A pesar de que gracias a ellas los naturalistas habían tenido la ocasión de poder estudiar de cerca centenares de especies a las que de otra manera difícilmente

95 William Lytle Schurz: El Galeón de Manila, Madrid, Instituto de Cooperación Iberoamericana, 1992; Carmen Yuste López: El comercio de Nueva España con Filipinas, 1590-1785, México, INAH, 1984; Marina Alfonso Mola y Carlos Martínez Shaw (eds.): El Galeón de Manila, Madrid, Aldeasa, 2000.

96 APRM, Patrimonio, Buen Retiro, 11746/19.

97 José Cosano Moyano: "El comercio directo Cádiz-Manila en navíos de la Real Armada (1765-1784)", en Boletín de la Real Academia de Córdoba de Ciencias, Bellas Artes y Nobles Artes, n. ${ }^{\circ}$ 102, Córdoba, 1984, pp. 183-219; Salvador Bernabéu Albert: El Pacífico ilustrado, Madrid, Mapfre, 1992 y Salvador Bernabéu Albert (ed.): El Pacífico español. Mitos, viajeros y rutas oceánicas, Madrid, Prosegur, 2003. 
hubieran tenido acceso, en seguida se dieron cuenta de lo artificiales que eran las condiciones en que estaban llevando a cabo tales observaciones. Comenzaron, entonces, a criticar sus instalaciones como insalubres y antinaturales, además de poco adecuadas para realizar su trabajo por estar más orientadas a impresionar y provocar la admiración del público que a fomentar el desarrollo de los saberes útiles..$^{98}$ No obstante, las invectivas no se detuvieron allí y, en 1797, el embajador francés en Madrid definía a las casas de fieras como "magníficas prisiones, obras maestras de la crueldad más aún que del lujo, que manifiestan la tiranía del hombre sin acreditar su poder". ${ }^{99} \mathrm{Y}$ es que, al igual que para los seres humanos, la privación de libertad, aunque fuese en un dorado encierro, pasó a considerarse también como un destino poco deseable para los animales salvajes, por lo que las críticas contra las ménageries reales arreciaron, adquiriendo además un sesgo moral y filosófico. En Francia, los enciclopedistas ya las habían atacado por constituir un derroche suntuario y, cuando estalló la revolución, la de Versalles se erigió ante los ojos del pueblo parisino en un símbolo más del boato, la opresión y la tiranía de la monarquía absoluta, siendo saqueada en varias ocasiones. ${ }^{100}$ Tal y como ha demostrado Louise E. Robbins, los animales salvajes de las colecciones reales y de la nobleza no salieron muy bien parados durante los años del terror a causa de la persistente asociación que la ideología prerrevolucionaria había acuñado entre su ferocidad y la de la nobleza opresora. ${ }^{101}$

En España, la decadencia y posterior desaparición de las colecciones zoológicas del Retiro y de los demás sitios reales no fueron fruto de la agitación revolucionaria, sino de las crisis bélicas que sacudieron a todo el continente durante el periodo napoleónico. El último envío importante de animales vivos desde América que hemos podido documentar data de $1789^{102} \mathrm{y}$, aunque durante los años siguientes aún se puedan encontrar noticias dispersas relativas a algunos ejemplares sueltos ${ }^{103}$, todo induce a sospechar que, a comienzos del siglo XIX, el colapso de la navegación y del comercio impidiera que los animales llegaran hasta las colecciones reales

98 Compendio de la Historia Natural, t. VIII, 1803, pág. 101-102; Ramón de Bru: Colección de láminas, t. II, "Al lector".

99 Barón de Bourgoing: Tableau de l Espagne Moderne, p. 530.

100 Denis Diderot y Jean le Rond D Alembert (eds.): Encyclopédie ou Dictionnaire raisonné des sciences, des arts et des métiers, París y Neuchâtel, 1765, t. 10, p. 330.

101 Robbins: Elephant Slaves, pp. 60-67 y 206-230.

102 AGI, Lima, 798.

103 AGI, Estado, 79/4 y 81/1 y 7. 
al mismo ritmo que lo habían hecho en sus mejores tiempos. ${ }^{104}$ Los apuros financieros, incluso, obligaban a la Corona a realizar economías y a priorizar ciertos gastos sobre otros, de manera que la fauna exótica de los reales sitios fue reduciéndose en número y en importancia conforme transcurría el reinado de Carlos IV, llegando a su total extinción durante la guerra de la Independencia. ${ }^{05}$ Sevilla, CSIC, 1972.

105 Gómez-Centurión Jiménez: "Exóticos y feroces”, pp. 20-21. 